\title{
Combination of CA125 and RECAF biomarkers for early detection of ovarian cancer
}

\author{
Janneta Tcherkassova $\cdot$ Carolina Abramovich • \\ Rafael Moro • Chen Chen • Ralph Schmit • \\ Angela Gerber • Ricardo Moro
}

Received: 27 April 2011 / Accepted: 29 April 2011 / Published online: 28 May 2011

(C) The Author(s) 2011. This article is published with open access at Springerlink.com

\begin{abstract}
Ovarian cancer can be cured in up to $90 \%$ of cases if diagnosed early. CA125, the most studied ovarian cancer biomarker, exhibits poor sensitivity for detecting early disease stages and low specificity to malignancy. RECAF, the alphafetoprotein receptor, is a wide-spectrum oncofetal antigen with clinical potential for cancer diagnosis, screening, and monitoring. This study evaluated the performance of RECAF as a diagnostic tool and the sensitivity of a combination of RECAF and CA125 to detect early stages of ovarian cancer at a cutoff resulting in $100 \%$ specificity among healthy women. This retrospective case-control study was designed to measure the serum levels of RECAF and CA125 in normal individuals $(n=$ 106) and cancer patients stages I/II (RECAF, $n=32$; CA125, $n=35)$ and III/IV (RECAF, $n=49$; CA125, $n=51$ ). A competitive chemiluminescence assay was developed to measure the circulating RECAF. To eliminate any false positives, we classified as positive any patient with a RECAF or a CA125 value higher than their respective $100 \%$ specificity cutoff. We have shown that RECAF discriminated cancer and healthy donors better than CA125, particularly in the early stages $\left(\mathrm{AUC}_{\mathrm{RECAF}}=0.96\right.$ and $\left.\mathrm{AUC}_{\mathrm{CA} 125}=0.805\right)$. CA125 sensitivity was lower in the early stages than in the advance stages; RECAF sensitivity was high at all stages. A combination of CA125 and RECAF detected three out of four early-stage patients, with no false positives. In conclusion, the
\end{abstract}

J. Tcherkassova - C. Abramovich • R. Moro • C. Chen •

R. Schmit • A. Gerber

Pacific Biosciences Research Centre,

Richmond, BC, Canada

R. Moro $(\bowtie)$

BioCurex,

215-7080 River Road,

Richmond, BC, Canada V6X 1X5

e-mail: rmoro@biocurex.com combination of RECAF and CA125 serum values provides the specificity and the sensitivity necessary to screen for ovarian cancer and in particular, to detect early stages of the disease.

Keywords RECAF - CA125 - Cancer markers - Ovarian cancer - Biomarkers · Alpha-fetoprotein - AFP - Receptor . Early detection $\cdot$ Diagnosis $\cdot$ Sensitivity $\cdot$ Specificity

\section{Introduction}

Early detection of cancer greatly increases the chances for a successful treatment. Among the tools developed during the past few decades, circulating biomarkers represent a simple non-invasive promising approach for improving detection, diagnostic, and management of some type of cancer $[1,2]$.

We have previously shown that RECAF, the receptor for the circulating fetal protein alpha-fetoprotein (AFP), is a wide-spectrum oncofetal antigen with a clinical potential for diagnosis, screening, and follow-up of treated patients [3]. RECAF plays a role in the internalization of circulating AFP by immature cells from most fetal tissues, and it has been suggested that the purpose of this internalization is to transport and to deliver polyunsaturated fatty acids into fetal cells [4-7]. RECAF is downregulated when embryonic cells and tissue structures approach a high degree of differentiation, thus preventing the uptake of AFP, even if the AFP blood concentration is still high and/or increasing [5]. We and others have shown that malignant cells regain the ability to take up AFP and demonstrated the expression of RECAF in a variety of cancer cells, but not in their mature counterparts [3, 8-11].

RECAF is not a single molecule; there are at least two main membrane fractions and two main soluble cytoplasmic 
components that can be released from cancer cells either actively or after the cells die [11-14]. Using a polyclonal antiRECAF antibody, we have previously developed a serum RECAF radioimmunoassay that demonstrated a higher concentration of serum RECAF in all types of cancer studied (breast, prostate, lung, stomach, and ovary) [3]. Importantly, the majority of benign tumors studied was RECAF negative, which indicates a potential use for RECAF in combination with tissue-specific markers for diagnosis of disease in which the prevalent tumor biomarker could be elevated in benign lesions. One such example is benign prostate hyperplasia, in which PSA is often elevated above the cutoff level for normal individuals [15].

Ovarian cancer can be cured in up to $90 \%$ of cases if diagnosed while still limited to the ovaries (stage I/II) [16]. However, early stages are asymptomatic, and the majority of patients is diagnosed with advanced disease (stage III/IV), in which only $20 \%$ or less can be cured [17]. Thus, despite being one tenth as common as breast cancer, ovarian cancer is three times more lethal [18]. According to the National Cancer Institute, it is estimated that in the USA alone, 21,880 women will be diagnosed with ovarian cancer and 13,850 women will die of it in 2010 (http://seer. cancer.gov/statfacts/html/ovary.html), placing ovarian cancer as the fourth leading cause of cancer death in women [18-21].

The development of earlier detection tests for ovarian cancer is challenging because of the low prevalence of the disease [18]. Current approaches to screening include transvaginal sonography (TVS), serum markers, and twostage strategies that use alterations in serum markers to prompt sonographic examination [22]. Among the serum markers, CA125, a mucin produced by ovarian cancer cells, has been studied most extensively [23-25]. However, CA125 exhibits poor sensitivity for detecting early-stage disease and has low specificity to malignancy [25].

To facilitate the discovery of novel biomarkers for early ovarian cancer detection, the USA Congress introduced the Ovarian Cancer Biomarker Act (legislation S. 2569), which mandate is to amend the Public Health Service Act to authorize the Director of the National Cancer Institute to make grants for the discovery and the validation of biomarkers for use in risk stratification for, and the early detection and screening of, ovarian cancer, as explained in the Office of Legislative Policy and Analysis website (http://olpa.od.nih.gov/legislation/110/pendinglegislation/ Ovarian_Cancer_Biomarker.asp.). However, it is worth noting that the likelihood that a single marker will fulfill the diagnostic efficiency required for its implementation as a population-based screening is hampered by the heterogeneity of ovarian cancer [26, 27], and therefore, a combination of biomarkers might be needed to enhance the sensitivity of serum assays [24, 28-30].
In this paper, we present a retrospective case-control study designed to evaluate the performance of: (1) RECAF as a diagnostic tool and (2) the combination of RECAF and CA125 to detect early stages (I and II) of ovarian cancer using a cutoff high enough to eliminate false positives among healthy women.

\section{Materials and methods}

\section{Cell lines}

All cell lines were obtained from the American Type Culture Collection (VA, USA) and were grown in RPMI containing $10 \%$ fetal calf serum (FCS, Invitrogen, Carlsbad, CA). MCF-7 is a human ductal breast carcinoma, HEP-G2 is a human hepatocellular carcinoma, and NS1 is a mouse myeloma cell line used as a partner for generating hybridomas.

Monoclonal antibody preparation

RECAF was purified from MCF-7 cell extracts using an AFPSepharose column. In short, cells were incubated for $1 \mathrm{~h}$ at $37^{\circ} \mathrm{C}$ in serum-free RPMI in order to deplete them of bovine AFP that they might have taken up from the FCS. The cells were then trypsinized and re-suspended at a concentration of $5 \times 10^{7} / \mathrm{ml}$ in TBS $(0.05 \mathrm{M}$ Tris- $\mathrm{HCl}+0.1 \mathrm{M} \mathrm{NaCl}, \mathrm{pH} 7.5)$. The suspension was then sonicated for $2 \mathrm{~min}$ in an ice bath using a Model 60 Sonic Dismembrator (Thermo Fisher Scientific, Mississauga, ON) at $32 \mathrm{~W}$, followed by centrifugation for $10 \mathrm{~min}$ at 14,000 rpm in an Eppendorf Microfuge. The total protein concentration of the supernatants was $7-12 \mathrm{mg} / \mathrm{ml}$, as determined with the BioRad Total Protein assay (BioRad, Hercules, CA). After adding 0.02\% thimerosal, the cell extracts were stored at $-20^{\circ} \mathrm{C}$ until they were used. RECAF was purified by affinity chromatography on an AFP-Sepharose column. The AFP used in the column was purified from the supernatant of HEP-G2 culture medium by affinity chromatography using an in-house produced anti-AFP monoclonal antibody and then conjugated to cyanogen bromide-activated Sepharose 4B (Sigma, St. Louis, MO). One milliliter of MCF-7 extract was incubated for $4 \mathrm{~h}$ at room temperature and under gentle agitation with $10 \mathrm{ml}$ of AFP-Sepharose in $0.05 \mathrm{M}$ Tris-HCl, pH 6.5. After thorough washing, the bound RECAF was eluted using $0.8 \mathrm{M} \mathrm{KCl}$ in the same buffer. The eluate was concentrated to $300-1,000 \mu \mathrm{g} / \mathrm{ml}$ using a Centricon spin 10,000 MWCO filter (Millipore Corporation, Billerica, MA).

For the generation of monoclonal anti-RECAF antibodies directed against the AFP-binding site, Balb/C mice primed with pristane were injected IP with $100 \mu \mathrm{g}$ of the eluent mixed 1:1 with Freund's complete adjuvant. Mice were boosted twice with the purified protein in incomplete 
adjuvant. Fusion was carried out using the NS1 myeloma cell line, following a procedure described by Taggart and Samloff [31] modified to use HAT for selection. The screening was carried out by Western blotting and ELISA on MCF-7 extract, as described previously [11]. Clones that recognized the same bands as AFP on Western blots were screened for binding to the AFP recognition site of RECAF by cross-competition studies [11]. In short, 96-well microtiter plates (LockWell MaxiSorp, NUNC, Thermo Fisher Scientific, Roskilde, Denmark) were coated with MFC-7 extract at $100 \mu \mathrm{g} / \mathrm{ml}$. For antibody inhibition of AFP binding to MCF-7 extract, twofold dilutions of antibody starting at $100 \mu \mathrm{g} / \mathrm{ml}$ were mixed with a constant concentration $(0.5 \mu \mathrm{g} / \mathrm{ml})$ of AFP biotinylated with NHSBiotin (Sigma), according to the manufacturer's instructions. The assay was revealed with streptavidin-peroxidase (KPL), developed with ABTS (KPL, Gaithersburg, MD), and read at $405 \mathrm{~nm}$. For AFP inhibition of antibody binding to MCF-7 extract, twofold dilutions of AFP starting at $500 \mu \mathrm{g} / \mathrm{ml}$ were mixed with a constant concentration $(0.5 \mu \mathrm{g} / \mathrm{ml})$ of an antibody-peroxidase conjugate produced by the Nakane and Kawaoi method [32]. The assay was developed with ABTS and read at $405 \mathrm{~nm}$. Monoclonal antibody typing was done using a kit from Zymed (San Francisco, CA), according to manufacturer's instructions.

Polyacrylamide gel electrophoresis and Western blots

Polyacrylamide gels containing 10\% sodium dodecyl sulfate (SDS) were used in a BioRad's polyacrylamide gel electrophoresis (PAGE) apparatus following the standard Laemmli's procedure [33]. The sample buffer consisted of $4 \mathrm{ml}$ of distilled water, $1 \mathrm{ml}$ of $0.5 \mathrm{M}$ Tris- $\mathrm{HCl}, 0.8 \mathrm{ml}$ glycerol, $1.6 \mathrm{ml}$ of $10 \%$ SDS, $0.4 \mathrm{ml}$ of $\beta$-mercaptoethanol, and $0.2 \mathrm{ml}$ of $0.05 \%(w / v)$ bromophenol blue. Gels were run for $2 \mathrm{~h}$ at a constant current of $0.2 \mathrm{Amp}(70-100 \mathrm{~V})$ in a $1 \times$ Tris-glycine running buffer in a Mini-Protein BioRad system. Western blots were carried out according to standard procedures, using a BioRad Mini-Transblot apparatus and $0.45 \mu \mathrm{m}$ pore nitrocellulose membranes (BioRad). After blocking the membranes with $1 \%$ BSA in TBS, the RECAF bands were evidenced by incubating the membrane with a suitable concentration of anti-RECAF antiserum or pure AFP-biotin. Color development was obtained using diaminobenzidine and $\mathrm{H}_{2} \mathrm{O}_{2}$ after incubating the membranes with a commercial conjugate (Sigma) of either streptavidin (for the biotinylated-AFP) or anti-mouse immunoglobulin labeled with horseradish peroxidase (Sigma).

RECAF labeling with acridinium

RECAF was labeled at a 40:1 molecules acridiniumRECAF ratio as follows: $1 \mathrm{ml}$ of RECAF (stock of
$200 \mu \mathrm{g} / \mathrm{ml}$ ) was mixed with $100 \mu \mathrm{l}$ DMSO to maintain acridinium (Cayman Chemical, Ann Arbor, MI) in solution. Then, $19 \mu$ of acridinium in DMF (stock of $4 \mathrm{mg} / \mathrm{ml}$ ) was added and mixed by inversion and incubated overnight protected from light. The RECAF-acridinium conjugate was dialyzed overnight at $4-6^{\circ} \mathrm{C}$ using Spectra/Por molecular porous membrane tubing $(12-14,000 \mathrm{mw}$ cutoff, $29 \mathrm{~mm}$ diameter; SpectrumLabs, Rancho Dominguez, CA) against two changes of 51 of PBS. Protein concentration was determined using BioRad DC Protein Assay (DC Protein Assay Kit II), followed by addition of ovalbumin to $0.01 \%$ and thimerosal to $0.02 \%$. The RECAF-acridinium solution was stored at $4-6^{\circ} \mathrm{C}$ protected from light until use. Under these conditions, the label RECAF remains functional for at least 90 days.

\section{CA125 immunoassay}

Circulating CA125 was measured using the "Enzyme Immunoassay Kit for Quantitative Determination of Antigen CA 125" following manufacturer's instructions (XEMA Research \& Production Co. Ltd.; Moscow, Russia, Cat K222-2).

\section{Chemiluminescence assay using acridinium-RECAF}

The test was designed as a solid-phase competitive immunoassay in which a constant amount of RECAFacridinium competed with the RECAF in the serum sample for binding to the anti-RECAF antibody immobilized onto the plastic plate: LockWell MaxiSorp 96-well plates were coated overnight at $4^{\circ} \mathrm{C}$ with $100 \mu \mathrm{l} /$ well containing $5 \mu \mathrm{g} / \mathrm{ml}$ of anti-RECAF purified antibody in $0.1 \mathrm{M}, \mathrm{pH} 9.5$, carbonate buffer. After washing twice with $\mathrm{dH}_{2} \mathrm{O}$ at room temperature, the wells were blocked for $2 \mathrm{~h}$ at $37^{\circ} \mathrm{C}$ with a proprietary buffer. A mixture of $50 \mu \mathrm{l}$ of serum sample and $50 \mu \mathrm{l}$ of RECAF-acridinium at $400 \mathrm{ng} / \mathrm{ml}$ was then transferred to the wells and incubated for $3 \mathrm{~h}$ at $37^{\circ} \mathrm{C}$. The wells were washed three times with $\mathrm{dH}_{2} \mathrm{O}$ at room temperature and read on a chemiluminometer (Beckman Coulter, Brea, CA).

\section{Standard curve}

We used several dilutions of the MCF-7 cell extract to create a standard curve calibrated in arbitrary RECAF units, which allowed us to normalize the RECAF measurements from one experiment to another. The dilutions were carried out in 3\% fish gelatin-TBS, and they were processed in the same manner as the serum samples. All sample readings were within the range of the standards. To interpolate values from the standard curve, we used the Logit/Log function. 


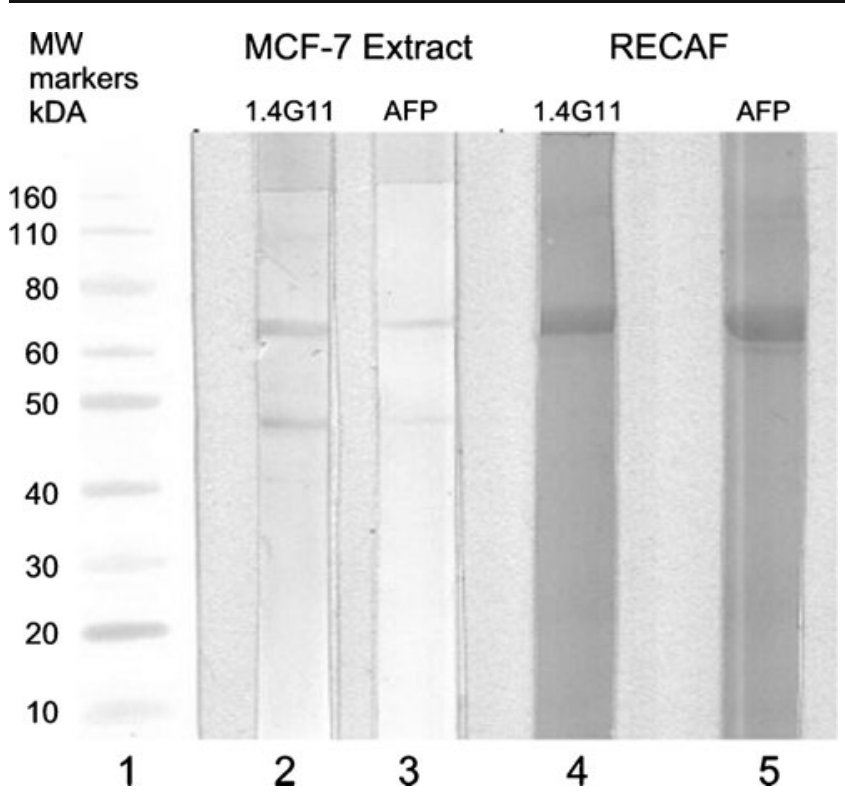

Fig. 1 Western blot analysis with anti-RECAF antibody and AFP. Lane 1 indicates MW markers, lanes 2 and 3 indicate MCF-7 whole extract reacted with Mab 1.4G11 and AFP, respectively, and lanes 4, 5, and 6 indicate purified RECAF reacted with Mab 1.4G11 and AFP, respectively

\section{Human sera}

Blood was collected and processed at the N.N. Blokhin Cancer Research Center in Moscow, Russia, according to the standard approved protocols. The serum samples from 80 confirmed ovarian cancer patients (stages $\mathrm{I} / \mathrm{II}=31$ and $\mathrm{III} / \mathrm{IV}=49$ ), and 105 healthy women were included in the study. All cancer serum samples were taken before administering treatment, and the diagnoses were histologically confirmed before starting this study. The samples were collected in sterile tubes with a clot activator, allowed to clot, centrifuged, frozen, and stored at $-20^{\circ} \mathrm{C}$. Before testing, the samples were thawed, heated for $30 \mathrm{~min}$ at $56^{\circ} \mathrm{C}$, and supplemented with $0.02 \%$ thimerosal.

Statistic analysis

For receiver operator characteristics (ROC) analysis [34], we used Analyse-it ${ }^{\circledR}$ (Analyse-it Software, Ltd.,
Leeds, UK). To classify a case as positive or negative, we first determined the cutoff value for each marker that resulted in $100 \%$ specificity in our data set and then we considered as positive any case that was above that corresponding cutoff for either marker. The determination coefficient $\left(r^{2}\right)$ between RECAF and CA125 serum values was determined using the Data Analysis tool in Microsoft Excel.

\section{Results}

Characterization of the anti-RECAF monoclonal antibody $1.4 \mathrm{G} 11$

Among the monoclonal antibodies that we evaluated, Mab 1.4G11 was selected for further studies. The screening criteria were similar to those previously published [11]. Briefly, a monoclonal antibody is considered to be directed against the AFP-binding site of RECAF if the three following conditions are met: (a) AFP and the antibody recognize the same isolated fractions, (b) AFP in excess inhibits the binding of the antibody to RECAF, and (c) an excess of the antibody inhibits the binding of AFP to its receptor. Western blot analysis of total MCF-7 extract and purified RECAF demonstrates that Mab1.4G11 and AFP recognize the same RECAF bands (Fig. 1). Mab1.4G11 and AFP competed with each other for binding to MCF-7 extracts, with maximal inhibition of $70 \%$ by Mab $1.4 \mathrm{G} 11$ against a fixed amount of AFP and of $85 \%$ by AFP against a fixed amount of Mab $1.4 \mathrm{G} 11$. In combination, these results demonstrate that Mab $1.4 \mathrm{G} 11$ is specific for RECAF and that it recognizes the AFP-binding site of the protein.

Measurement of RECAF and CA125 serum levels in ovarian cancer patients and control

To measure serum levels of RECAF, we developed a novel chemiluminescence assay. Forty blind samples distributed

Table 1 Descriptive statistics of serum RECAF and CA125 in normal and cancer patients

\begin{tabular}{|c|c|c|c|c|c|c|c|c|}
\hline & Samples & $n$ & Median & 95 Percentile & Min & Max & Mean & S.D. \\
\hline \multirow[t]{4}{*}{ RECAF (units) } & Healthy controls & 106 & 2.106 & 5,381 & 0,031 & 7,421 & 2,280 & 1,805 \\
\hline & Cancer all stages & 81 & 7.664 & 11,305 & 1,917 & 17,216 & 7,805 & 2,582 \\
\hline & Cancer stage I/II & 32 & 8.112 & 10,043 & 2,142 & 17,216 & 8,082 & 2,715 \\
\hline & Cancer stage III/IV & 49 & 7.393 & 12,061 & 1,917 & 14,214 & 7,624 & 2,503 \\
\hline \multirow[t]{4}{*}{ CA125 (units) } & Healthy controls & 106 & 6.2 & 28.00 & 0.00 & 35.00 & 9.885 & 9.532 \\
\hline & Cancer all stages & 86 & 164.27 & $1,681.44$ & -0.02 & $1,889.53$ & 391.91 & 516.81 \\
\hline & Cancer stage I/II & 35 & 60.20 & $1,308.29$ & -0.02 & $1,763.06$ & 273.33 & 423.91 \\
\hline & Cancer stage III/IV & 51 & 251.88 & $1,779.82$ & 5.41 & $1,889.53$ & 473.29 & 561.48 \\
\hline
\end{tabular}



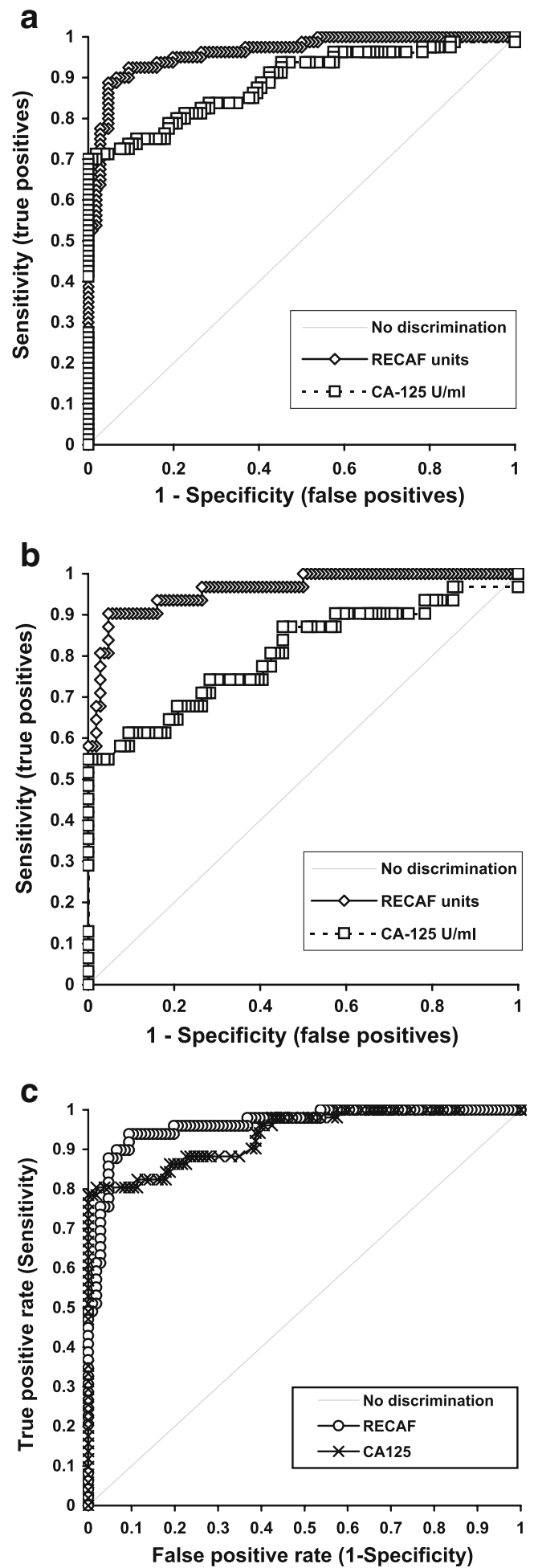

Fig. 2 ROC analysis of RECAF and CA125. ROC curves of normal individuals and cancer patients at a all stages (RECAF AUC $=0.96$, CA125 AUC $=0.889)$, $\mathbf{b}$ stages I/II (RECAF AUC $=0.96$, CA125 AUC $=$ 0.805), and $\mathbf{c}$ stages III/IV (RECAF AUC $=0.96$, CA125 AUC $=0.96$ )

within the range of measured RECAF values were repeatedly tested to determine the intra- and intervariability of the assay. The intra-assay coefficient of variation $(\mathrm{CV})$ was $\leq 8 \%$, and the inter-assay $\mathrm{CV}$ was less than $6.5 \%$.

Table 1 shows the descriptive statistics of RECAF and CA125 values in the serum of healthy controls as well as patients with various stages of ovarian cancer. Linear regression studies demonstrated a low determination coefficient between the RECAF and CA125 values in all the samples $\left(r^{2}=0.1318[\mathrm{r}=0.36]\right.$ and in the ones containing only cancer patients $\left(r^{2}=0.0056[r=0.07]\right.$. The low correlation coefficient indicates that a combination of the two markers would improve their individual cancer detection performance.

ROC analysis Figure 2 shows the RECAF and CA125 ROC curves for all cancer stages (Fig. 2a), stages I and II (Fig. 2b) and III and IV (Fig. 2c). The power to discriminate between cancer and healthy donors is noticeable higher for RECAF, particularly in early stages of cancer, where the performance of CA125 is lower (AUC for RECAF was 0.96 vs 0.805 for CA125). Importantly, Fig. 3a
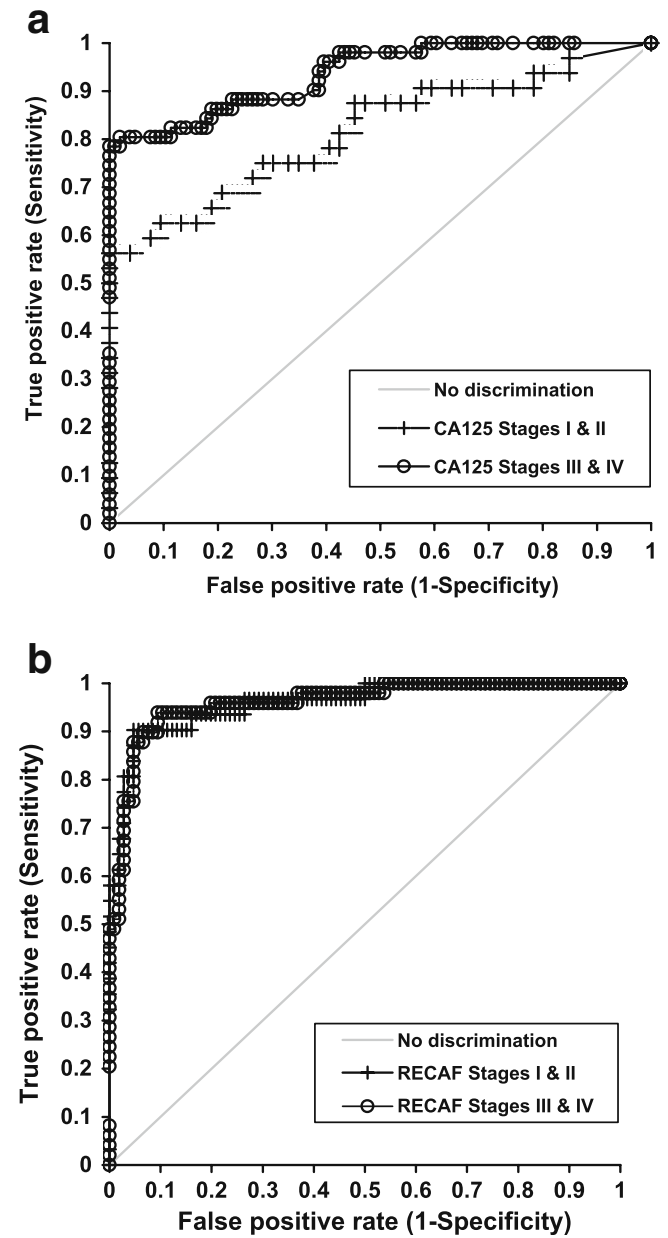

Fig. 3 ROC analysis of cancer patients at stages I/II and III/IV. ROC curves for a CA125 and b RECAF 
RECAF and CA-125 Distribution in Ovarian Cancer and Normal Samples

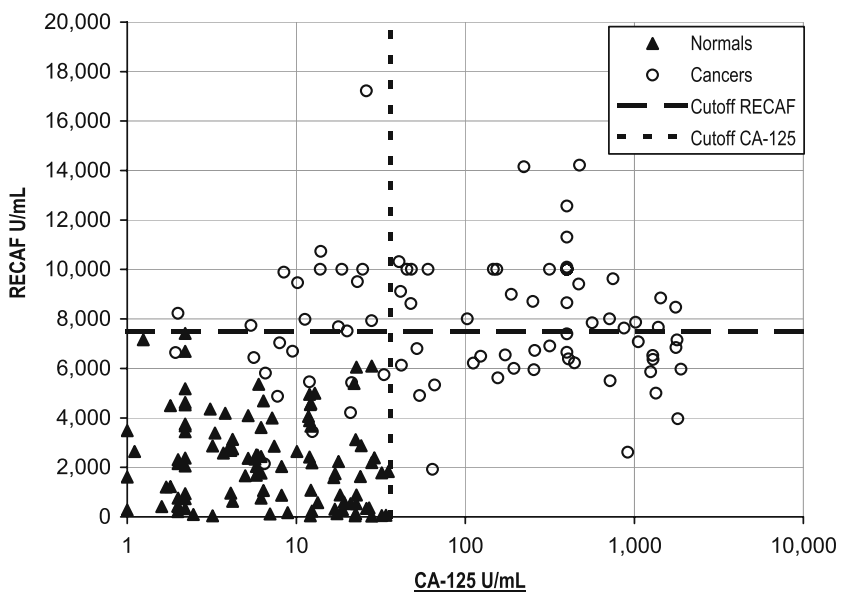

Fig. 4 Specificity cutoff value (100\%) for CA125 and RECAF. CA125 showed a larger range of values than RECAF and required a log scale on the $x$-axis

shows that whereas the sensitivity of CA125 is lower in early stages as compared with advanced disease, RECAF sensitivity is high at any stage (Fig. 3b). Together, these results point at a potential use of RECAF serum values for ovarian cancer diagnostic.

Combination of serum values of RECAF and CA125

Given the rarity of ovarian cancer, even with a high specific test, very low levels of false positive classification would result in an unacceptable number of women incorrectly categorized as positive for the disease. Based on the lack of correlation in the circulating levels of CA125 and RECAF, we set up to determine whether their combination could improve the sensitivity and the specificity of ovarian cancer detection. For that purpose, we used a simple combination method, which classifies as positive any patient with a RECAF or CA125 value higher than the respective $100 \%$ specificity cutoff. This high cutoff reduces the sensitivity of the individual tests, but as there is no correlation between marker values, we expected that the overall sensitivity of the combination would reach clinically useful values.

In our group of samples, the $100 \%$ specificity cutoff value for CA125 was 36 and 7,500 units/ml for RECAF
(Fig. 4). Table 2 shows the sensitivities of each or a combination of the biomarkers for the different cancer stages at $100 \%$ specificity. The addition of RECAF to CA125 increased the sensitivity of ovarian cancer detection from $70 \%$ to $83 \%$ for all cancer samples and from $79.6 \%$ to 88.2 for stage III/IV. For cancer stage I/II, where screening is most useful, the marker combination detected $76 \%$ of cancers, compared with $58.1 \%$ detected by CA125 alone. Lowering the specificity of RECAF to $97 \%$, while keeping the same CA125 cutoff, increased the sensitivity for stage I/II to $86 \%$. Together, these results demonstrate that, by combining serum values of CA125 and RECAF, it is feasible to obtain a screening test that will detect three out of four earlystage ovarian cancer with no false positives among normal women.

\section{Discussion}

In this paper, we reported the potential use of RECAF serum values as a diagnostic tool for ovarian cancer and the combination of RECAF and CA125 serum values as a novel screening strategy to discriminate normal and ovarian cancer patients with high sensitivity without compromise in specificity. Importantly, in this retrospective case-control study, high sensitivity values were attained with the combination of markers at early stages, where the 5-year survival rate is $90 \%$, as opposed to $20 \%$ for stages III and IV.

Ovarian cancer is known as the silent killer. Early symptoms, if any, are vague, and the majority of patients present with late-stage disease. The incidence of the disease in average-risk women is 40 per 100,000 [18]. With this relatively low frequency, any successful screening strategy must not only have a sensitivity of greater than $75 \%$ for early-stage disease, but also have a specificity of $99.6 \%$ [35] to significantly decrease the probability of possible complications associated with surgical confirmatory procedures. A number of approaches have been proposed to improve the specificity of CA125 for early detection. In an initial screening test for ovarian cancer in experimental multimodal multistep screening programs, women with elevated CA125 levels generally undergo further evaluation using TVS [36]. However, the success of this strategy is
Table 2 Sensitivity of the tests at $100 \%$ specificity

\begin{tabular}{llllll}
\hline \multirow{2}{*}{ Test } & Cutoff & Specificity & \multicolumn{2}{l}{ Sensitivity } & \\
\cline { 4 - 5 } & & & All stages & Stage I/II & Stage III/IV \\
\hline RECAF & 7,500 units & $100 \%$ & $52.5 \%$ & $54.8 \%$ & $49.0 \%$ \\
CA125 & 36.00 units & $100 \%$ & $70.0 \%$ & $58.1 \%$ & $79.6 \%$ \\
COMBINATION & & $100 \%$ & $83.0 \%$ & $75.7 \%$ & $88.2 \%$ \\
\hline
\end{tabular}


questionable. For example, in a study by Liede et al., women at elevated risk were screened annually with examinations, CA125 and TVS. During the study period, six of the eight cancers diagnosed were found to be in advanced stages [37]. In another study of 4,526 women at elevated risk for ovarian cancer, TVS was performed every 6 months. During the study period, there were ten ovarian, fallopian tube, and primary peritoneal cancers, all of which were diagnosed in advanced stages [38]. Indeed, a drawback of this program is that its sensitivity as a whole is limited by the sensitivity of the initial screening biomarker used. Unfortunately, CA125 is elevated above reference levels in only approximately $50 \%$ of patients with clinically detectable, early-stage disease [39], which is consistent with the $56 \%$ sensitivity found in our study for stages I and II. Moreover, preliminary results from the Prostate, Lung, Colorectal, and Ovarian Cancer Screening Trial shows that TVU and CA125, alone or in combination, cannot only detect ovarian cancer, but can also produce many false-positive test results, causing needless surgery. Thus, a cost-effective test that does not result in a low positive predictive value and excessive morbidity from unnecessary surgery is highly desirable.

In the retrospective case-control study reported here, serum RECAF was detected in elevated levels in ovarian cancer patients when compared with normal individuals, with levels of RECAF higher in stage III/IV than I/II. Using ROC analysis, we showed that both RECAF and CA125 were able to discriminate between normal and cancer patients, although RECAF performed better, especially in early-stage disease. Moreover, the specificity of the RECAF test did not change and was high at early and late stages; whereas, the sensitivity of CA125 was lower in earlier stages than in advance disease. Interestingly, similar observations were seen with the levels of RECAF in prostate and breast cancer (in preparation).

Combining CA125 with other markers represents a promising approach for improving screening efficiency. Some of the combinations examined so far show promising results; however, their level of sensitivity/specificity is not appropriate for use in a population-based screening [38, 40]. For example, in a recent study, the addition of serum HE4 values to CA125 increased the sensitivity of the assay for early detection from $73.2 \%$ to $82.9 \%$ and the specificity from $79.2 \%$ to $87.6 \%$ [41]. The combination of CA 125 with B7-H4 increased the sensitivity of early detection from $52 \%$ for CA 125 alone to $65 \%$ at $97 \%$ specificity [42]. The possibility of combining RECAF with other markers is intriguing, in particular because of the lack of correlation between circulating concentration and cancer stage. The combination of RECAF and CA125 at a specificity of $100 \%$ increased the sensitivity of ovarian cancer detection from $70 \%$ to $83 \%$ for all cancer samples and from $79.6 \%$ to
$88.2 \%$ for stage III/IV. Importantly, for cancer stage I/II, the marker combination detected $76 \%$ of cancers, compared with $58.1 \%$ detected by CA125 alone.

Our data show that the combination of RECAF and CA125 serum values provides the specificity and the sensitivity necessary to screen for ovarian cancer, and in particular, to detect early stages, where cure rates are the highest. It should be kept in mind, however, that while ovarian cancers can be detected with a combination of CA125 and RECAF serum values, not all patients detected with this method will have ovarian cancer, since RECAF is elevated in many other cancer types [3]. Moreover, this study did not include benign conditions. However, given the fact that the cutoff value was set in a way that excluded healthy individuals, any patient testing positive is likely to have a pathology that at a minimum would require diagnosis and in some cases, treatment. In those cases, the result of the test should be considered as beneficial for the patient, regardless of the specific pathology involved.

In conclusion, this study provides the framework for the development of a strategy that could provide a costeffective and sensitive approach to detect early stages of ovarian cancer and therefore, reduce disease-associated mortality.

Open Access This article is distributed under the terms of the Creative Commons Attribution Noncommercial License which permits any noncommercial use, distribution, and reproduction in any medium, provided the original author(s) and source are credited.

\section{References}

1. Baker SG. Improving the biomarker pipeline to develop and evaluate cancer screening tests. J Natl Cancer Inst. 2009;101:1116-9.

2. Pepe MS, Etzioni R, Feng Z, Potter JD, Thompson ML, Thornquist $\mathrm{M}$, et al. Phases of biomarker development for early detection of cancer. J Natl Cancer Inst. 2001;93:1054-61.

3. Moro R, Tcherkassova J, Song E, Shen G, Moro R, Schmid R, Hu X, Kummer A, Chen C (2005) A new broad-spectrum cancer marker. In-Vitro Diagnostic Technology.

4. Abelev GI, Perova SD, Khramkova NI, Postnikova ZA, Irlin IS. Production of embryonal alpha-globulin by transplantable mouse hepatomas. Transplantation. 1963;1:174-80.

5. Deutsch HF. Chemistry and biology of alpha-fetoprotein. Adv Cancer Res. 1991;56:253-312.

6. Ruoslahti E, Seppala M. Alpha-fetoprotein in cancer and fetal development. Adv Cancer Res. 1979;29:275-346.

7. Trojan J, Uriel J. Immunocytochemical localization of alphafetoprotein in the developing rat brain. Oncodev Biol Med. 1980;1:107-11.

8. Geuskens M, Naval J, Uriel J. Ultrastructural studies of the intracellular translocation of endocytosed alpha-foetoprotein (AFP) by cytochemistry and of the uptake of $3 \mathrm{H}$-arachidonic acid bound to AFP by autoradiography in rat rhabdomyosarcoma cells. J Cell Physiol. 1986;128:389-96. 
9. Uriel J, Poupon MF, Geuskens M. Alphafoetoprotein uptake by cloned cell lines derived from a nickel-induced rat rhabdomyosarcoma. Br J Cancer. 1983;48:261-9.

10. Uriel J, Villacampa MJ, Moro R, Naval J, Failly-Crepin C. Uptake of radiolabeled alpha-fetoprotein by mouse mammary carcinomas and its usefulness in tumor scintigraphy. Cancer Res. 1984;44:5314-9.

11. Moro R, Tamaoki T, Wegmann TG, Longenecker BM, Laderoute MP. Monoclonal antibodies directed against a widespread oncofetal antigen: the alpha-fetoprotein receptor. Tumour Biol. 1993;14:11630 .

12. Kanevsky V, Pozdnyakova LP, Aksenova OA, Severin SE, Katukov V, Severin ES. Isolation and characterization of AFPbinding proteins from tumor and fetal human tissues. Biochem Mol Biol Int. 1997;41:1143-51.

13. Suzuki $Y$, Zeng CQ, Alpert E. Isolation and partial characterization of a specific alpha-fetoprotein receptor on human monocytes. J Clin Invest. 1992;90:1530-6.

14. Torres JM, Darracq N, Uriel J. Membrane proteins from lymphoblastoid cells showing cross-affinity for alpha-fetoprotein and albumin. Isolation and characterization. Biochim Biophys Acta. 1992;1159:60-6.

15. Tosoian J, Loeb S. PSA and beyond: the past, present, and future of investigative biomarkers for prostate cancer. ScientificWorldJournal. 2010;10:1919-31.

16. Campos SM, Ghosh S. A current review of targeted therapeutics for ovarian cancer. J Oncol. 2010;2010:149362.

17. Bast Jr RC, Hennessy B, Mills GB. The biology of ovarian cancer: new opportunities for translation. Nat Rev Cancer. 2009;9:415-28.

18. Jemal A, Siegel R, Ward E, Hao Y, Xu J, Thun MJ. Cancer statistics, 2009. CA Cancer J Clin. 2009;59:225-49.

19. Parkin DM, Pisani P, Ferlay J. Estimates of the worldwide incidence of eighteen major cancers in 1985. Int $\mathrm{J}$ Cancer. 1993;54:594-606.

20. Boyle P, Maisonneuve P, Autier P. Update on cancer control in women. Int J Gynaecol Obstet. 2000;70:263-303.

21. Beard CM, Hartmann LC, Atkinson EJ, O'Brien PC, Malkasian GD, Keeney GL, et al. The epidemiology of ovarian cancer: a population-based study in Olmsted County, Minnesota, 19351991. Ann Epidemiol. 2000;10:14-23.

22. Bast Jr RC. Status of tumor markers in ovarian cancer screening. J Clin Oncol. 2003;21:200s $-5 \mathrm{~s}$.

23. Jacobs I, Bast Jr RC. The CA 125 tumour-associated antigen: a review of the literature. Hum Reprod. 1989;4:1-12.

24. Berek JS, Bast Jr RC. Ovarian cancer screening. The use of serial complementary tumor markers to improve sensitivity and specificity for early detection. Cancer. 1995;76:2092-6.

25. Bast Jr RC, Badgwell D, Lu Z, Marquez R, Rosen D, Liu J, et al. New tumor markers: Ca125 and beyond. Int J Gynecol Cancer. 2005;15 Suppl 3:274-81.

26. Pieretti M, Hopenhayn-Rich C, Khattar NH, Cao Y, Huang B, Tucker TC. Heterogeneity of ovarian cancer: relationships among histological group, stage of disease, tumor markers, patient characteristics, and survival. Cancer Invest. 2002;20:11-23.

27. McAlpine JN, Eisenkop SM, Spirtos NM. Tumor heterogeneity in ovarian cancer as demonstrated by in vitro chemoresistance assays. Gynecol Oncol. 2008;110:360-4.

28. Woolas RP, Conaway MR, Xu F, Jacobs IJ, Yu Y, Daly L, et al. Combinations of multiple serum markers are superior to individual assays for discriminating malignant from benign pelvic masses. Gynecol Oncol. 1995;59:111-6.

29. Crump C, McIntosh MW, Urban N, Anderson G, Karlan BY. Ovarian cancer tumor marker behavior in asymptomatic healthy women: implications for screening. Cancer Epidemiol Biomarkers Prev. 2000;9:1107-11.

30. Moore RG, McMeekin DS, Brown AK, DiSilvestro P, Miller MC, Allard WJ, et al. A novel multiple marker bioassay utilizing HE4 and CA125 for the prediction of ovarian cancer in patients with a pelvic mass. Gynecol Oncol. 2009;112:40-6.

31. Taggart RT, Samloff IM. Stable antibody-producing murine hybridomas. Science. 1983;219:1228-30.

32. Nakane PK, Kawaoi A. Peroxidase-labeled antibody. A new method of conjugation. J Histochem Cytochem. 1974;22:1084-91.

33. Laemmli UK. Cleavage of structural proteins during the assembly of the head of bacteriophage T4. Nature. 1970;227:680-5.

34. Linden A. Measuring diagnostic and predictive accuracy in disease management: an introduction to receiver operating characteristic (ROC) analysis. J Eval Clin Pract. 2006;12:132-9.

35. Skates SJ, Xu FJ, Yu YH, Sjovall K, Einhorn N, Chang Y, et al. Toward an optimal algorithm for ovarian cancer screening with longitudinal tumor markers. Cancer. 1995;76:2004-10.

36. Einhorn N, Sjovall K, Knapp RC, Hall P, Scully RE, Bast Jr RC, et al. Prospective evaluation of serum CA 125 levels for early detection of ovarian cancer. Obstet Gynecol. 1992;80:14-8.

37. Liede A, Karlan BY, Baldwin RL, Platt LD, Kuperstein G, Narod SA. Cancer incidence in a population of Jewish women at risk of ovarian cancer. J Clin Oncol. 2002;20:1570-7.

38. Baron AT, Boardman CH, Lafky JM, Rademaker A, Liu D, Fishman DA, et al. Soluble epidermal growth factor receptor (sEGFR) [corrected] and cancer antigen 125 (CA125) as screening and diagnostic tests for epithelial ovarian cancer. Cancer Epidemiol Biomarkers Prev. 2005;14:306-18.

39. Gupta D, Lis CG. Role of CA125 in predicting ovarian cancer survival - a review of the epidemiological literature. J Ovarian Res. 2009;2:13.

40. McIntosh MW, Drescher C, Karlan B, Scholler N, Urban N, Hellstrom KE, et al. Combining CA 125 and SMR serum markers for diagnosis and early detection of ovarian carcinoma. Gynecol Oncol. 2004;95:9-15.

41. Abdel-Azeez HA, Labib HA, Sharaf SM, Refai AN. He4 and mesothelin: Novel biomarkers of ovarian carcinoma in patients with pelvic masses. Asian Pac J Cancer Prev. 2011;11:111-6.

42. Simon I, Zhuo S, Corral L, Diamandis EP, Sarno MJ, Wolfert RL, et al. B7-H4 is a novel membrane-bound protein and a candidate serum and tissue biomarker for ovarian cancer. Cancer Res. 2006;66:1570-5. 